УДК 519.816+621.1.016

DOI https://doi.org/10.32851/tnv-tech.2021.6.10

\title{
АЛГОРИТМ ЕВОЛЮЦІЙНОГО ПОШУКУ БАГАТОКРИТЕРІАЛЬНИХ РІШЕНЬ ДЛЯ ОБІГРІВУ ВІДКРИТОЇ ПРОМИСЛОВОЇ ПЛОЩАДКИ 3 ТРУБЧАСТИМИ ГАЗОВИМИ НАГРІВАЧАМИ
}

\author{
Шаптала Д.є. - кандидат технічних наук, \\ доцент кафедри інформаційних технологій та загальної підготовки \\ Дніпровського технологічного університету «ШАГ» \\ ORCID ID: 0000-0002-1045-0801 \\ Дубровський С.C. - кандидат технічних наук, \\ ректор Дніпровського технологічного університету «ШАГ» \\ ORCID ID: 0000-0001-6957-6620 \\ Іродов В.Ф. - доктор технічних наук, \\ профресор кафедри інформаційних технологій та загальної підготовки \\ Дніпровського технологічного університету «ШАГ» \\ ORCID ID: 0000-0001-8772-9862
}

Ефективний обігрів відкритих промислових площадок - актуальна проблема використання промислових підприємств в Україні при реконструкції діючих підприємств. При опаленні промислових площчадок в цеехах промислових підприємств не має потреби створювати систему опалення всього цеху, а необхідно обігріти лише відкриту площадку в иеху який не опалюється. Для опалення відкритих плошадок використовуються системи променевого опалення. Але променеве опалення відкритих площадок показало, щуо незважаючи на значні променеві теплові потоки охолоджене повітря проривається знизу на відкриту площадку. Нещодавно було запропоновано використовувати комбінований засіб опалення відкритих промислових площзадок - на гранищі зони обігріву використовуються вузько направлено променевий обігрів, а також створення повітряної завіси від холодного повітря на рівні підлоги. Для трубчастих газових нагрівачів розташованих у горизонтальних каналах розроблена математична модель, яка може бути застосована для прийняття рішень в системі обігріву відкритої промислової площадки. Але для иієї математичної моделі не були розроблені критерії прийняття оптимальних рішень $і$ не розроблений алгоритм вирімення задач оптимізачії обігріву відкритої площзадки з трубчастими газовими нагрівачами у каналах для створення повітряних завіс на границі зони обігріву. Розроблені критерії оптимізації обігріву відкритих площадок з трубчастими газовими нагрівачами в каналах. Для математичного моделювання теплообмінних процесів у трубчастих нагрівачах з подачею повітря для його підігріву застосовані раніше отримані експериментальні результати наукового дослідження авторів. Для математичного моделювання ефективності трубчастого нагрівача у якості повітряної завіси використовувались результати експериментальних досліджень повітряних завіс, які представлені у літературі. Сформульований вибір оптимальних багатокритеріальних рішень застосовуючи вибір у вигляді блокування. Для пошуку багатокритеріальних рішень при оптимізації обігріву відкритої площзадки з трубчастими газовими нагрівачами в горизонтальному каналі розроблений алгоритм еволючуійного пошуку з функиією відбору у вигляді блокування. Отримані результати чисельного пошуку багатокритеріальних рішень наведеної задачі оптимізації, з яких видно збіжність чисельних результатів пошуку рішень при застосуванні в алгоритмі декількох гилок еволюиійного процесу.

Ключові слова: трубчастий газовий нагрівач, підземний горизонтальний канал, багатокритеріальна оптимізація, алгоритм еволюиійного пошуку.

Shaptala D.E., Dubrovsky S.S., Irodov V.F. Algorithm of evolutionary search for multicriterial solutions for heating of an open industrial site with tabular gas heating

Effective heating of open industrial sites is an urgent problem of using industrial enterprises in Ukraine in the reconstruction of existing enterprises. When heating industrial sites in the shops of industrial enterprises there is no need to create a heating system of the whole shop, and it is 
necessary to heat only the open area in the shop which is not heated. Radiant heating systems are used for heating open areas. But radiant heating of open areas has shown that despite significant radiant heat fluxes, cooled air penetrates from below to the open area. Recently, it was proposed to use a combined means of heating open industrial sites - on the border of the heating zone are used narrowly directed beam heating, as well as the creation of an air curtain of cold air at floor level. A mathematical model has been developed for tubular gas heaters located in horizontal channels, which can be used for decision-making in the heating system of an open industrial site. But for this mathematical model, the criteria for making optimal decisions have not been developed and no algorithm for solving problems of optimization of open site heating with tubular gas heaters in the channels to create air curtains at the boundary of the heating zone. Criteria for optimizing the heating of open areas with tubular gas heaters in the channels have been developed. For mathematical modeling of heat exchange processes in tubular heaters with air supply for its heating, the previously obtained experimental results of the authors' scientific research are used. For mathematical modeling of the efficiency of the tubular heater as an air curtain, the results of experimental studies of air curtains, which are presented in the literature, were used. The choice of optimal multicriteria solutions is formulated using the choice in the form of blocking. To find multi-criteria solutions for optimizing the heating of an open area with tubular gas heaters in a horizontal channel, an evolutionary search algorithm with a selection function in the form of blocking has been developed. The results of numerical search of multicriteria solutions of the given optimization problem are obtained, from which the convergence of numerical results of search of solutions at application in algorithm of several branches of evolutionary process is visible.

Key words: tubular gas heater, underground horizontal channel, multicriteria optimization, evolutionary search algorithm.

Постановка проблеми. Прилади та системи променевого опалення промислових підприємств використовуються в Україні на основі електричної енергії або газового палива, а в останній час - енергії деревини у вигляді паливних гранул (пелет). Протягом останніх років розроблені наукові та методичні основи використання систем газового променевого опалення для промислових підприємств. Застосування променевого опалення промислових підприємств виявило існування проблеми у забезпеченні обігріву відкритих площадок у цих підприємствах. Виявилось, що обігрів відкритих площадок, незважаючи на значні потоки променевої енергії, не забезпечують створення комфортних умов особливо в нижній частини опалювального простору через проникнення холодного повітря зовні промислової площадки. Нещодавно було запропоновано використовувати комбінований засіб опалення відкритих промислових площадок - на границі зони обігріву використовуються вузько направлено променевий обігрів, а також створення повітряної завіси від холодного повітря на рівні підлоги. Для трубчастих газових нагрівачів розташованих у горизонтальних каналах розроблена математична модель, яка може бути застосована для прийняття рішень в системі обігріву відкритої промислової площадки. Але для цієї математичної моделі не були розроблені критерії прийняття оптимальних рішень і не розроблений алгоритм вирішення задач оптимізації обігріву відкритої площадки з трубчастими газовими нагрівачами у каналах для створення повітряних завіс на границі зони обігріву.

Аналіз останніх досліджень і публікацій. Особливості проєктування систем опалення з інфрачервоними трубчастими нагрівачами викладені в [1]. А у [2] викладені основні положення проєктування та оптимізації обігріву промислових приміщень. У цих роботах розглядалось опалення всього промислового приміщення у якого є огороджувальні конструкції і які не дозволяють проникати всередину значним витратам холодного повітря. Але ситуація змінюється, якщо розглядається обігрів відкритої промислової площадки, яка може бути розташована всередині великого цеху або зовні. Практика використання систем променевого обігріву відкритих площадок показала, що забезпечити комфортні умови 
на відкритій площадці завдяки тільки променевому обігріву - не реально. Спеціальне дослідження [3] підкреслило ці особливості обігріву відкритих площадок. У цій роботі методом наведено результати чисельного аналізу параметрів системи радіаційного обігріву відкритої платформи - розміром $10 \times 75$ м. Температура радіатора розміром $0,3 \times 9$ м становила $600-900$ К. Температура атмосферного повітря змінювалась у діапазоні від -10 до $+10^{\circ} \mathrm{C}$ при швидкості вітру до $5 \mathrm{~m} / \mathrm{c}$. За умов комфортного обігріву людини приймалася температура на рівні їі голови (175 cм). Встановлено, що променевий обігрів не зовсім забезпечує комфортні умови на відкритій площадці. Так, в [3] встановлено, що температура на рівні верхівки голови людини становить від $2-3^{\circ} \mathrm{C}$ до $16-18^{\circ} \mathrm{C}$ при розташуванні радіаторів на висоті 4-8 м від поверхні платформи на навколишньому просторі. температура повітря $0^{\circ} \mathrm{C}$ та швидкість вітру $0,5-5 \mathrm{~m} / \mathrm{c}$. Показано, що при зниженні температури повітря до $-10^{\circ} \mathrm{C}$ потрібне встановлення вітрозахисту. Нещодавно було запропоновано використовувати комбінований засіб опалення відкритих промислових площадок - на границі зони обігріву використовуються вузько направлено променевий обігрів, а також створення повітряної завіси від холодного повітря на рівні підлоги. Ці технічні рішення проілюстровані на рис. 1 та рис. 2. Для створення повітряної завіси використовуються трубчасті газові нагрівачі, які розташовані у горизонтальних каналах (рис. 1). Нагріте повітря підіймається від поверхні трубчастого нагрівача (рис. 2) і утворює повітряну завісу.

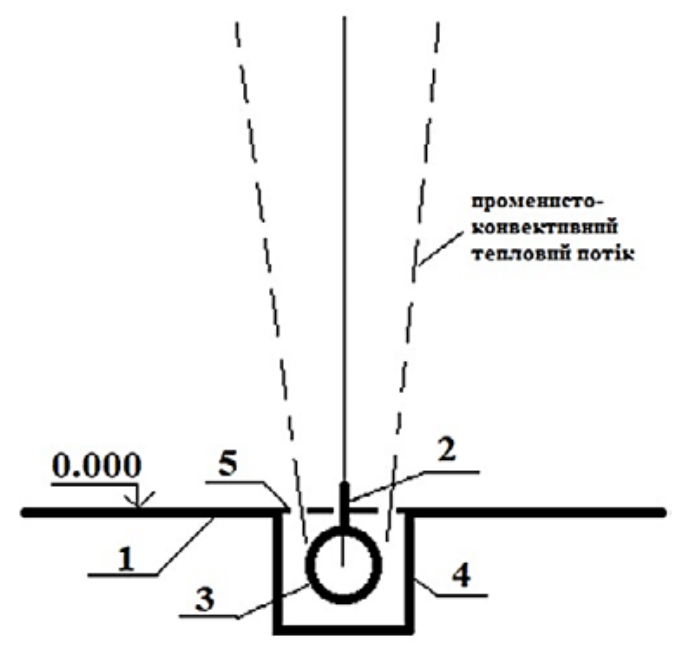

Рис. 1. Трубчастий газові нагрівач у горизонтальному каналі з використанням вузько направленого променевого обігріву

Процесам руху повітря і теплообміну при застосуванні повітряних завіс присвячено багато робіт [4-11]. Найбільш послідовне викладення наукових результатів 3 аналізу аеро- і термодинамічних процесів у отворі з повітряно-тепловою завісою наведено в [4]. Ю.В. Іванов [5] у своїй роботі найбільш повно вивчив розповсюдження струменів у потоці, що зносить. У його роботі розглянуті траєкторії одиночного прямокутного, плоского та круглого струменів в обмеженому та вільному поперечних потоках. Для того, щоб створити плоский струмінь, використовувались сопла 3 шириною 0,9; 2,7; 4 мм. Експерименти проводились при двох значеннях відношення абсолютних температур T2/T1 $=1$ и 2. Зміни відношення 


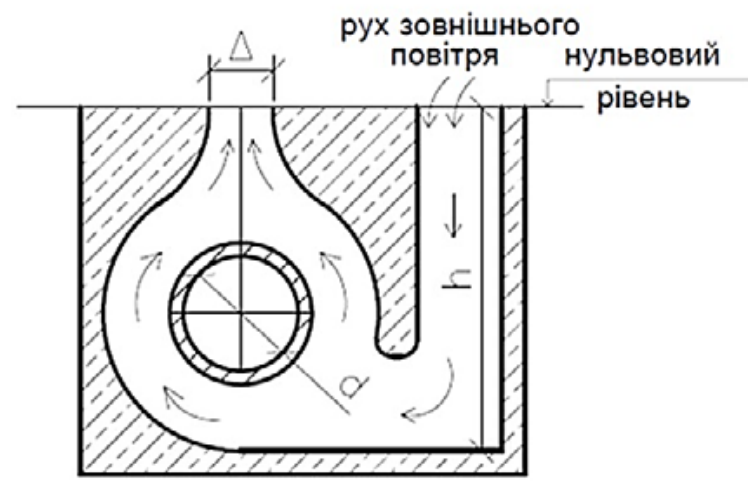

Рис. 2. Трубчастий газові нагрівач у горизонтальному каналі для створення повітряної завіси на рівні підлоги

критичних енергій струменя к потоку, що зносить, складали від 400 до 12,5. Експерименти проводились с соплами, встановленими під кутами: $\mathrm{a}=0^{\circ} \mathrm{C}$ и $\mathrm{a}=30^{\circ} \mathrm{C}$. Розвиток струменя показаний на рис. 3 .

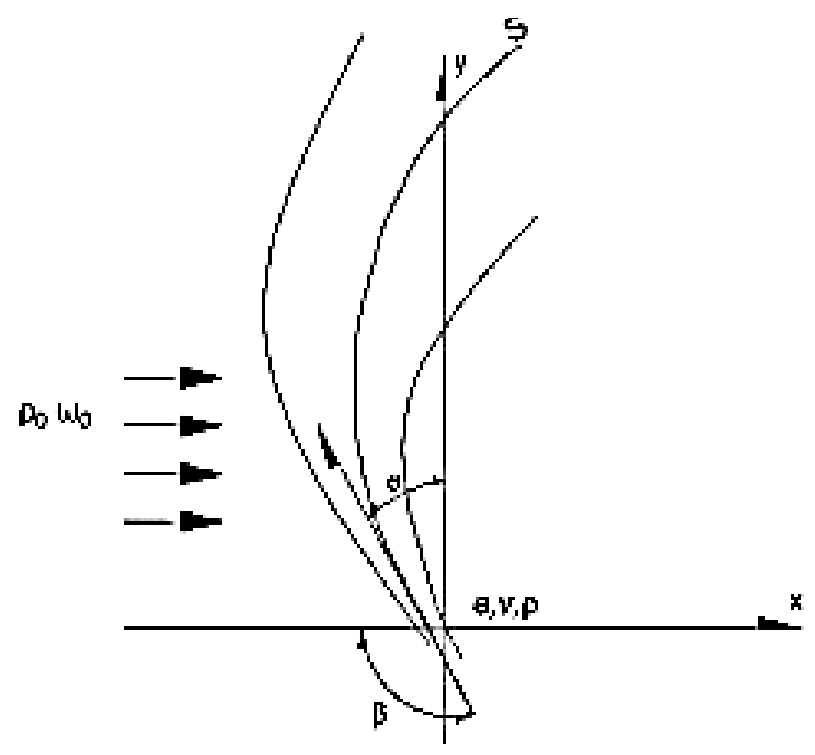

Рис. 3. Схема розвитку струменя у поперечному потоияі

Після обробки експериментальних даних Ю.В. Іванов запропонував рівняння для розрахунку плоского струменя в потоці, яке мають вигляд:

$$
\frac{a_{x}}{\mathrm{~B}_{0}}=1.9\left(\frac{\rho_{0} \omega_{0}}{\rho v^{2}}\right)\left(\frac{a_{\mathrm{y}}}{\mathrm{B}_{0}}\right)+\frac{a_{\mathrm{y}}}{\mathrm{B}_{0}} \operatorname{Ctg} \beta,
$$

де $y$ - відстань від вісі сопла по нормалі до потоку, що зносить; $x$ - відстань від вісі сопла у напрямі потоку, що зносить; $\mathrm{B}_{0}$ - половина ширини сопла; $\omega_{0}$ - швидкість потоку, що зносить; $v^{2}$ - швидкість витоку газу; $\rho$ - щільність газу; $\rho_{0}-$ щільність потоку, що зносить; $a$ - коефіцієнт структури струменя. 
Лінія, що поєднує точки з максимальними значеннями швидкостей прийнята Ю.В. Івановим як вісь струменю.

Постановка завдання. Мета - розробити критерії та алгоритм прийняття рішень для трубчастого газового нагрівача, який використовується для повітряної завіси при обігріву відкритої площадки промислового підприємства.

Викладення основного матеріалу дослідження. Для знаходження оптимального рішення для трубчастих газових нагрівачів, які розташовуються у горизонтальних каналах і застосовуються для повітряних завіс на границі опалювальної площадки, був використаний підхід з застосуванням бінарних відношень вибору, у відповідності з [12; 13]. У дослідженні використовується математична модель трубчастого газового нагрівача $з$ екраном розташованим в горизонтальному каналі.

Математична модель теплових та гідравлічних режимів роботи трубчастих газових нагрівачів з екраном представлена [14] у вигляді:

$$
\begin{gathered}
M=\rho w F=\text { const, } \\
\rho=\rho R T \\
d p=-\frac{1}{D} \cdot \rho \cdot \frac{w^{2}}{2} \cdot d x+\left(\rho_{a}-\rho\right) \cdot g \cdot d h \\
d Q_{1 K}=\pi D d x \alpha_{1}\left(T-T_{w}\right), \\
d Q_{1 \Pi}=\pi D d x c_{o} \varepsilon\left(T^{4}-T_{w}^{4}\right) 10^{(-8)}, \\
d Q_{1}=d Q_{1 K}+d Q_{1 \Pi}, \\
d Q_{2 K}=\pi D d x \alpha_{1}\left(T_{w}-T_{e}\right), \\
d Q_{2 \Pi}=\pi D d x c_{o} \varepsilon_{w}\left(T_{w}^{4}-T_{e}^{4}\right) 10^{(-8)}, \\
d Q_{2 K}=\pi D d x \alpha_{1}\left(T_{w}-T_{e}\right), \\
d Q_{3}=d Q_{3 K}+d Q_{3 \Pi}, \\
d Q_{3 \Pi}=\pi D d x c_{o} \varepsilon_{e}\left(T_{e}^{4}-T_{o}^{4}\right) 10^{(-8)}, \\
d Q_{3}=d Q_{3 K}+d Q_{3 \Pi}, \\
d Q_{1}=d Q_{2}=d Q_{3}, \\
d\left(\rho w F C_{p} T\right)=-d Q_{1}+d Q_{0} \quad \text { for } \quad 0<x<L_{f}, \\
d\left(\rho w F C_{p} T\right)=-d Q_{1} \quad \text { for } \quad x>L_{f}, \\
d Q_{0} / d x=Q_{0} / S_{f} 2 \pi \cdot y_{f}(x) \text { for } \quad 0<x<L_{f}, \\
d p=-\frac{1}{D} \cdot \rho \cdot \frac{w^{2}}{2} \cdot d x+\left(\rho_{a}-\rho\right) \cdot g \cdot d h, \\
d \rho=(d p-\rho R d t) /(R T) \\
d w=(-w F d p-\rho w d F) /(\rho F), \\
\int d p_{i}\left(x_{i}\right)+\Delta p_{5}+\Delta p_{6}=0
\end{gathered}
$$

Основні параметри оптимізації - це $x^{1}-$ теплова потужність нагрівача, кВт; $x^{2}$ - витрата повітря, ${ }^{3} /$ год; $x^{3}-$ діаметр трубчастого нагрівача, м; $x^{4}-$ діаметр екрану, м; $x^{5}$ - довжина нагрівача, м; $x^{6}$ - довжина екрану, м.

Шукаючи рішення задачі оптимізації з математичною моделі (2)-(21), як знаходження найбільш переважного рішення, можна замість цього шукати блокуюче 
рішення за трьома критеріями. У такому випадку відношення бінарного вибору (22) можна записати як:

$$
\begin{gathered}
x_{1} R_{S l} y_{1} \equiv\left[E_{2}\left(x_{1}\right) \leq 0 \text { and } E_{2}\left(y_{1}\right)>0\right] \text { and }\left[E_{3}\left(x_{1}\right) \leq 0 \text { and } E_{3}\left(y_{1}\right)>0\right] \\
\text { and }\left[E_{1}\left(x_{1}\right) \geq E_{1}\left(y_{1}\right)\right] .
\end{gathered}
$$

Операторна схема алгоритму еволюційного пошуку представлена на рис. 4:

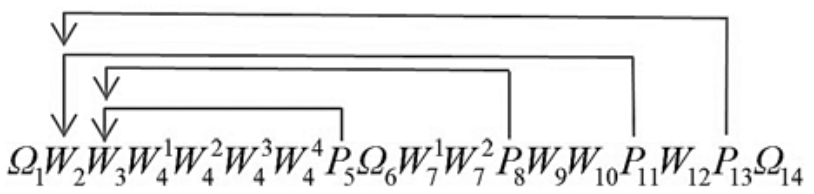

Рис. 4. Операторна схема алгоритму еволюційного пошуку

де: $\Omega_{1}$ - початок пошуку; $W_{1}$ - генерація можливих значень $x=\left\{x^{1}, x^{3}, \ldots, x^{6}\right\}$; $W_{3}$ - генерація можливого значення температури нагрівача на конкретному кроці інтегрування по довжині нагрівача; $W_{4}{ }^{1}-$ обчислення витрат тепла $d Q_{1 K}, d Q_{1 \Pi}, d Q_{1}$; $W_{4}^{2}$ - обчислення витрат тепла $d Q_{2 K}, d Q_{1 \Gamma} ; W_{4}^{3}$ - обчислення температури поверхні екрану $T_{e} ; W_{4}^{4}$ - обчислення теплових витрат $d Q_{3 K}, d Q_{3 \Pi} ; P_{5}-$ чи досягнутий необхідний тепловий баланс на поверхні екрану? Якщо «НІ», то перехід на $W_{3}$; $\Omega_{6}$ - початок інтегрування рівнянь $(5 ; 6 ; 7) ; W_{7}^{1}$ - обчислення параметрів руху і теплопередачі на початок ділянки; $W_{7}^{2}$ - обчислення параметрів руху і теплопередачі на кінці ділянки; $P_{8}-$ завершений процес інтегрування на кінець нагрівача? Якщо «НІ», то перехід до $W_{3} ; W_{9}$ - обчислення трьох цільових функцій: цільової

Таблиця 1

Процес еволюційного пошуку рішень за оптимізації трубчастого газового

\begin{tabular}{|c|c|c|c|c|c|c|c|c|c|}
\hline \multirow{2}{*}{ Ітерації } & \multicolumn{6}{|c|}{ Параметри оптимізації X(I) } & \multicolumn{3}{|c|}{ Функції - E } \\
\hline & $x^{1}$ & $x^{2}$ & $x^{3}$ & $x^{4}$ & $x^{5}$ & $x^{6}$ & E1 & E2 & E3 \\
\hline \multirow{6}{*}{$\mathbf{K I T}=1$} & 3.518 & 592.056 & 0.180 & 0.321 & 73.416 & 25.191 & 0.595 & 0.000 & 0.125 \\
\hline & 3.894 & 631.677 & 0.149 & 0.298 & 70.887 & 23.178 & 0.525 & 0.000 & 1.105 \\
\hline & 3.849 & 594.436 & 0.180 & 0.325 & 80.495 & 28.241 & 0.601 & 0.000 & 0.194 \\
\hline & 4.011 & 619.410 & 0.179 & 0.321 & 81.686 & 27.335 & 0.587 & 0.000 & 0.191 \\
\hline & 3.835 & 571.418 & 0.180 & 0.290 & 76.128 & 32.977 & 0.610 & 0.000 & 0.225 \\
\hline & 3.643 & 567.528 & 0.173 & 0.285 & 76.542 & 32.648 & 0.597 & 0.000 & 0.190 \\
\hline \multirow{6}{*}{$K I T=2$} & 2.863 & 547.761 & 0.180 & 0.328 & 78.954 & 29.200 & 0.611 & 0.000 & 0.000 \\
\hline & 3.472 & 599.576 & 0.177 & 0.350 & 70.661 & 25.288 & 0.596 & 0.000 & 0.017 \\
\hline & 3.758 & 596.245 & 0.180 & 0.349 & 71.335 & 25.340 & 0.609 & 0.000 & 0.164 \\
\hline & 3.715 & 584.310 & 0.180 & 0.348 & 80.931 & 26.029 & 0.615 & 0.000 & 0.172 \\
\hline & 3.485 & 544.538 & 0.180 & 0.350 & 74.191 & 26.945 & 0.636 & 0.000 & 0.194 \\
\hline & 3.551 & 537.271 & 0.180 & 0.321 & 84.564 & 35.413 & 0.631 & 0.000 & 0.208 \\
\hline \multirow{5}{*}{$K I T=15$} & 2.000 & 347.216 & 0.180 & 0.350 & 90.589 & 30.841 & 0.739 & 0.000 & 0.000 \\
\hline & 2.000 & 347.217 & 0.180 & 0.350 & 69.723 & 29.083 & 0.739 & 0.000 & 0.000 \\
\hline & 2.000 & 347.217 & 0.180 & 0.350 & 69.723 & 29.083 & 0.739 & 0.000 & 0.000 \\
\hline & 2.000 & 347.240 & 0.180 & 0.350 & 64.000 & 26.414 & 0.739 & 0.000 & 0.000 \\
\hline & 2.000 & 347.267 & 0.180 & 0.350 & 87.901 & 25.169 & 0.739 & 0.000 & 0.000 \\
\hline
\end{tabular}
нагрівача з екраном для повітряній завіси відкритої площадки 
функції $E_{l}(x)=\eta$ - безрозмірна ефективність, $E_{2}(x)$ інтегральне відхилення струменя по вісі від максимального значення у відповідності з (1):

$$
E_{2}(x)=\Sigma a b s(x в i d x-x \max ) .
$$

де $E_{31}(x)$ - безрозмірне відхилення втрат тиску в нагрівачі від максимального значення:

$$
E_{3}(x)=E_{31}(x)+E_{32}(x) .
$$

$E_{32}(x)$ - безрозмірне відхилення температурного перепаду на екрані нагрівача від максимального перепаду температур.

$$
E_{32}(x)=\Sigma\left(\Delta T_{e}\left(x_{i}\right) / T_{\max },\right.
$$

де $\Delta T_{e}\left(x_{i}\right)=-\left(T_{e}\left(x_{i}\right)\right.$ ج $\left.T_{\text {max }}\right)$ якщо $\left(T_{e}\left(x_{i}\right) \leq T_{\text {max }}\right.$ та $\Delta T_{e}\left(x_{i}\right)=0$ якщо $T_{e}\left(x_{i}\right) \geq T_{\max }$;

$W_{10}-$ вибір $N_{k}$ найбільш привабливих рішень для кожної гилки $N_{E}$ еволюції; $P_{11}-$ генерація можливих рішень для кожної гилки еволюції? Якщо «НІ», то перехід до $W_{2} ; \mathrm{W}_{12}$ - обчислення параметрів пошуку для кожного кроку ітерації; $P_{13}-$ досягнення заданої точності отримання найбільш привабливих рішень? Якщо «НІ», то перехід до $W_{2} ; \Omega_{14}-$ кінець пошуку.

Бінарне відношення вибору приймалося у формі (22).

Результати еволюційного пошуку для вирішення задачі оптимізації трубчастого газового нагрівача з екраном, який застосовується при обігріві відкритої площадки представлені в табл. 1.

Висновки й перспективи подальших досліджень. Сформульовані критерії оптимізації рішень для трубчастих газових нагрівачів, що застосовуються для повітряних завіс на границі виділеної відкритої промислової площадки. Розроблений алгоритм багатокритеріальної оптимізації для прийняття рішень при застосуванні трубчатих газових нагрівачів для повітряних завіс відкритих промислових площадок. Проведені чисельні розрахунки багатокритеріальної оптимізації по розробленому алгоритму еволюційного пошуку. Розрахунки показали, що розроблений алгоритм еволюційного пошуку дозволяє отримати важливі параметри трубчастих газових нагрівачів з екраном, при застосуванні у повітряних завісах для відкритих площадках.

\section{СПИСОК ВИКОРИСТАНОӤ ЛІТЕРАТУРИ:}

1. Солод Л.В. Проектирование систем отопления с инфракрасными трубчатыми газовыми обогревателями. Строительство. Материаловедение. Машиностроение. Серия «Энергетика, экология, компьютерные технологии в строительстве». 2013. Вып. 70. С. 202-208.

2. Ахрамович А.П., Дмитриев Г.М., Колос В.П. Оптимизация систем инфракрасного обогрева производственных цехов. Промышиленная теплотехника. 2012. T. 34. № 2. С. 77-80.

3. Процессы лучистого теплопереноса при обогреве открытых площадок / А.А. Редько, И.А. Редько, Ю.А. Бурда, А.Ф. Редько, С.В. Павловский. Инженернофизический журнал. 2020. Т. 93. № 6. С. 1576-1583.

4. Григорьев А.Ю., Жигновская Д.В. Обзор и анализ аэро- и термодинамических процессов в проеме с воздушно-тепловой завесой. Научный журнал Национального исследовательского университета ИТМО. Серия «Холодильная техника и кондиционирование». № 4. 2016. С. 6-15.

5. Иванов Ю.В. Плоская струя во внешнем поперечном потоке. Известия Академии наук Эстонской Советской Соичилистической Республики. Таллин, 1953. T. II. № 2. C. 33-68. 
6. Палатник И.Б., Темирбаев Д.Ж. Закономерности распространения осесимметричной воздушной струи в сносящем однородном потоке. Проблемы теплоэнергетики и прикладной теплофизики. 1967. Вып. 4. С. 68-82.

7. Newman B.G. The Deflexion of Plane Jets by Adjacent Boundaries Coanda Effect Boundary Layer and Flow Control. Pergamon Press. Oxford. 1961. Vol. 1. P. 232-264.

8. Визель Я.М., Мостинский И.Л. Искривление струи в сносящем потоке. Инженерно-физический журнал. 1965. Т. 8. № 2. С. 58-67.

9. Шепелев И.А. Аэродинамика воздушных потоков в помещении. Москва, $1978.145 \mathrm{c}$.

10. Шандров Г.С. Истечение из канала в неподвижную и движущуюся среду. Журнал технической физики. 1957. Т. 27. № 1. С. 92-108.

11. Григорьев А.Ю., Рубцов И.А. Моделирование пусковых режимов работы тепловой завесы. Вестник Международной академии холода. 2012. № 3. С. 32-35.

12. Юдин Д.Б. Вычислительные методы теории принятия решений. Москва : Наука, 1989. 320 с.

13. Yudin D.B. Generalized mathematical programming. Economics and Mathematical Methods. 1984. Vol. 20. P. 148-167.

14. Development of evolutionary search algorithms with binary choice relations for pellet tubular heaters / V. Irodov, M. Shaptala, K. Dudkin, D. Shaptala, H. Prokafieva. Eastern-European Journal of Enterprise Technologies. 2021. No. 3/8 (111). P. 50-59.

15. Experimental Simulation and Multiobjective Optimization of the Work of a Pellet Burner for a Tubular Gas Heater / V.F. Irodov, R.V. Barsuk, G. Ya. Chornomorets, A.A. Chernoyvan. Journal of Engineering Physics and Thermophysics. 2021. Vol. 94. P. 227-233.

\section{REFERENCES:}

1. Solod, L.V. (2013) Proektirovanie system otoplenie c infrakrasnimi trubchatimi gasovimi nagrevatelyami [Design of heating systems with infrared tubular gas heaters]. Stroitelsvo. Materialovedenie. Mashinostroenie. Seriya: Energetika, ekologiya, kompyuternie tekhnologie v stroitelsnve - Construction. Materials Science. Mechanical engineering. Series: Energy, ecology, computer technologies in construction, 70, 202-208 [in Russian].

2. Ahramovich, A.P., Dmitriev, G.M., Kolos, V.P. (2012) Optimizatsiya cictem infrakrasnogo obogreva proizvodstvenih tsehov [Optimization of infrared heating systems for production halls]. Prom. teplotehnika - Industrial heating technology, 2, 77-80 [in Russian].

3. Redko, A.A., Redko, I.A., Burda, Ya.A., Redko, A.F., Pavlovskii, S.V. (2020) Protsessy luchistogo teploperenosa pri obogreve otkrytykh ploshchadok [ Radiant heat transfer processes when heating open areas]. Inzhenerno-fizicheskiy zhurnal - Engineering Physics Journal, 6, 1576-1583 [in Russian].

4. Grigoriev, A.Yu., Zhiganovskaya, D.V. (2016) Obzor i analiz aero- i termodinamicheskikh protsessov v proyeme s vozdushno-teplovoy zavesoy [Review and analysis of aerodynamic and thermodynamic processes in the opening with an air-thermal curtain]. Nauchnyy zhurnal NIU ITMO. Seriya "Kholodil'naya tekhnika i konditsionirovaniye"Scientific journal of NRU ITMO. Series "Refrigeration and air conditioning", 4, 6-15 [in Russian].

5. Ivanov, Yu.V. (1953) Ploskaya struya vo vneshnem poperechnom potoke [Plane jet in external cross flow] Izvestiya AN ESSR. Tallin - Izvestia of the Academy of Sciences of the ESSR. Tallinn, 2, 33-68 [in Russian].

6. Palatnik, I.B., Temirbaev, D.Zh. (1967) Zakonomernosti rasprostraneniya osesimmetrichnoy vozdushnoy strui v snosyashchem odnorodnom potoke [Regularities of propagation of an axisymmetric air jet in a drifting homogeneous flow] Problemy teploenergetiki $i$ prikladnoy teplofiziki - [Problems of heat power engineering and applied thermal physics], 4, 68-82 [in Russian]. 
7. Newman, B.G. (1961) The Deflexion of Plane Jets by Adjacent Boundaries Coanda Effect Boundary Layer and Flow Control. Pergamon Press. Oxford, 1, 232-264.

8. Vizel, Ya.M., Mostinskii, I.L. (1965) Iskrivleniye strui v snosyashchem potoke [Curvature of a jet in a sweeping stream] Inzhenerno-fizicheskiy zhurnal - Engineering Physics Journal, 2, 58-67 [in Russian].

9. Shepelev, I.A. (1978) Aerodinamika vozdushnykh potokov v pomeshchenii [Indoor air flow aerodynamics]. Moscow, Russia: Nauka [in Russian].

10. Shandrov, G.S. (1957) Istecheniye iz kanala v nepodvizhnuyu i dvizhuyushchuyusya sredu [Outflow from a channel into a stationary and moving medium] Zhurnal tekhnicheskoy fiziki - Journal of Technical Physics, 1, 92-108 [in Russian].

11. Grigoriev, A.Yu., Rubtsov, I.A. (2012) Modelirovaniye puskovykh rezhimov raboty teplovoy zavesy [ Modeling of starting modes of operation of the thermal curtain] Vestnik Mezhdunarodnoy akademii kholoda - Bulletin of the International Academy of Refrigeration, 3, 32-35 [in Russian].

12. Yudin, D.B. (1989) Vychislitel'nyye metody teorii prinyatiya resheniy [Computational methods of decision theory]. Moscow: Nauka. Gl. red. Fiz.-mat. lit. [in Russian].

13. Yudin, D.B. (1984) Generalized mathematical programming. Economics and Mathematical Methods, 20, 148-167.

14. Irodov, V., Shaptala, M., Dudkin, K., Shaptala, D., Prokafieva, H. (2021) Development of evolutionary search algorithms with binary choice relations for pellet tubular heaters. Eastern-European Journal of Enterprise Technologies, 3/8 (111), 50-59.

15. Irodov, V.F., Barsuk, R.V., Chornomorets, G.Ya., Chernoyvan, A.A. (2021) Experimental Simulation and Multiobjective Optimization of the Work of a Pellet Burner for a Tubular Gas Heater. Journal of Engineering Physics and Thermophysics, 94, 227-233. 